RESEARCH PAPER

\title{
"Some convincing arguments to pass back to nervous customers": the role of the tobacco retailer in the Australian tobacco industry's smoker reassurance campaign 1950-1978
}

\section{A Tofler, S Chapman}

Tobacco Control 2003;12(Suppl III):iii7-iii12

See end of article for authors' affiliations

.....................

Correspondence to: Professor Simon Chapman, School of Public Health, University of Sydney, Building A 27, Sydney, NSW 2006, Australia; simonchapman@ health.usyd.edu.au
S ince the release of an estimated 40 million pages of internal tobacco industry documents, a growing body of research has explored ways in which the tobacco manufacturing industry planned and acted to counteract the rising tide of information that smoking posed a serious risk to smoker's health. ${ }^{12}$ The industry embarked on a global campaign that it termed "smoker reassurance". This involved the use of publicity tours by consultant scientists to the industry who dissented from the mainstream of medical opinion, public campaigns centred on the industry's public position that "more research is needed", and promulgation of the notion that any alleged health effects from smoking were confounded by other causes. These efforts were overseen by tobacco industry lawyers advising on what could and could not be said. ${ }^{3}$

While the manufacturing industry's role in this misleading conduct is well documented, the part played by retailers is less understood. Tobacco retailers have a unique opportunity to interact with smokers on each occasion of purchase. In Australia today impersonal supermarkets, often employing a high turnover of casual staff, dominate tobacco retailing with $35 \%$ of the \$A7.1 billion retail market. ${ }^{4}$ However, in the first three decades after the advent of major adverse publicity about smoking and health (1950-1980) most smokers bought their cigarettes from dedicated tobacconists in more personalised retail environments. Today, these tobacconists command only $20 \%$ of the Australian retail trade. These shops are generally independently owned and run by small businessmen, and supplied by tobacco companies and their wholesalers via van salesmen.

The salesmen have always acted as conduits from the tobacco manufacturing industry to the retailer, introducing and recommending new products and discounted lines, advocating sales pitches and gimmicks. Another paper in this supplement details the vital role played in Australia today by company retailing representatives in in-store, below-the-line marketing. ${ }^{5}$ Importantly, and something virtually neglected in tobacco control research, these salesmen and delivery workers may have also passed on messages from the tobacco industry, which they would have hoped the shopkeepers would in turn pass on to smokers to counteract the potential effects of publicity about research on smoking and health. Later, as governments began introducing tobacco control measures, the van salesmen supplied campaigning material that sought to enlist smokers in the industry's opposition to issues like excise tax rises, smoking restrictions, and even advertising bans.

Another major conduit for the tobacco industry was trade journals distributed to retailers by their trade associations. These included the Retail Tobacconist of NSW (1944 till July 1966, thereafter The Australian Retail Tobacconist-still published today), the Tobacco Trade Journal (Queensland, 19401974), The Tobacco Journal (South Australia, 1935-1974), and the Tobacco Journal (Victoria, 1930-1974). These journals were circulated to all members of tobacco retail organisations in their respective states.

\section{METHODS}

We obtained a trunk full of these journals from an antique dealer who had purchased them from the deceased estate of a former tobacconist. The collection included largely complete volumes of the journals from: Queensland (1952-3, 1957-61, 1970-74); South Australia (1950-72); Victoria (1961-1974); and nationally (1954-58, 1969-78). We examined the journals in this large convenience sample for articles consistent with the manufacturing industry's efforts to counter messages about smoking and health, and for illustrative material on 
how tobacconists might attract non-smokers, particularly young people and women.

Both authors independently reviewed each issue, noting candidate articles. AT then extracted all relevant statements and quotes which were then chronologically catalogued under two broad headings (health; and marketing to youth and women). We then selected exemplary instances for use in the paper.

\section{RESULTS}

The tobacco retail journals outlined promotional and sales strategies for tobacconists. The producers of these journals actively championed their promotional material, and encouraged retailers to utilise it for merchandising purposes. It follows that this information may have become a significant part of the sales strategies of many tobacconists, and in the process this information may have been passed on to customers-the smoking public.

The journals contained tear-out price lists for all brands for display in shops. ${ }^{6}$ As such, the journals are an invaluable source for scholarship requiring detailed information on brands and prices going back decades. They routinely provided general guidance regarding the operation of a small business such as choosing staff, store tidiness, window decoration, and other methods of attracting and retaining customers. Generic articles syndicated from writers on selling techniques were common, as were reports about the trade associations' and manufacturers' activities.

Information regarding current issues pertinent to the industry were also covered, with advice given to retailers to display such notices to their customers. For example, when a ban on smoking on public transport was announced retailers were urged: "If you object to this attempt to dictate personal habits by Transport Minister Cox put up in your shop the notice on the opposite page." ${ }^{\prime 7}$ Retailers were advised to consult the travelling tobacco salesmen about policy matters: "Retailers who are in doubt about the health warning requirement on cigarette packets, should discuss the matter with their friendly van-salesman." ${ }^{8}$

\section{Counteracting smoking and health scares}

Both retailers and van salesmen were seen by the industry as partners in their efforts to counteract the rising tide of negative publicity about smoking, that had been given a major boost by the publication of epidemiological studies on smoking and lung cancer by Doll and Hill ${ }^{9}$ and Wynder and Graham $^{10}$ in 1950. Considerable momentum then developed via publicity surrounding the publication of the reports on smoking and health of the Royal College of Physicians of London $(1962)^{11}$ and the US Surgeon General (1964). ${ }^{12}$ These reports were openly attacked in articles in the retail journals, and retailers advised on counteracting propaganda to pass on to their customers. A 1953 article was said to give: “...an illuminating and effective answer to some of the British medical men and others who have been trying to frighten the smoking public. It gives retailers some convincing arguments to pass back to nervous customers." ${ }^{13}$

And in 1955: “...These objections can be handled satisfactorily on a personal basis by the average salesman...The intelligent handling of this objection can aid the industry in explaining the true facts, and while so doing destroy the poison of half-truths, innuendos, doubletalk and outright falsehoods forming the current bulk of conversation of this topic...Remember, your customer is quite apt to repeat your story to his customers, to those he might hear objecting or repeating this unfavorable propaganda." ${ }^{\prime 14}$

\section{Air pollution, not smoking}

Perhaps the most recurring theme in health related articles throughout the journals was that other agents, particularly air pollution and petrol fumes, caused cancer (box 1). Promoting information about other suspected carcinogens promised to fulfil two main objectives. Often these reports were about ordinary, banal agents and activities said to be carcinogenic. These are likely to have contributed to the notion that risk-phobic scientists believed "everything" caused cancer, and that warnings about tobacco therefore needed to be discounted when considered against such an extreme orientation. By routinely highlighting other alleged causes of cancer in conjunction with a publicity agenda that the industry was dedicated to uncovering the "real" causes of lung cancer, the tobacco industry positioned itself as responsible, not bending to fashionable theories but dedicated to uncovering the truth.

Public health scaremongers were said to be constantly adding everyday items to their lists of dangerous agents that caused cancer (box 2).

Genetic susceptibility and confounding from other illness were also emphasised. Dr Charles Mayo said that the

\section{Box 1: Air pollution, not tobacco, causes lung cancer}

- 1959: "Addressing a meeting of the United States Southern Society of Clinical Surgeons, Dr William Rienhoff, associated [sic] professor of surgery at Johns Hopkins University School of Medicine, said that after operating on nearly 800 cases of lung cancer he had found "no scrap of evidence" to indicate that cigarettes were more likely to cause lung cancer than air pollutants that every one breathed, such as exhaust fumes." 15

- 1962: Sir Clement Price-Thomas, an eminent surgeon said to have operated on King George VI la heavy smoker who died of lung cancer) was quoted as saying: "But, there are other causes of cancer atmospheric pollution, for instance, all those factories belching out smoke. And here's another benzpyrene - found in the fumes put out by motor cars..."

- 1963: "Dr. Geoffrey Dean..., blames air pollution for the disease. And he concludes: There is little risk in moderate smoking - unless the air is also dirty. ${ }^{117}$

- 1964: "The Japanese cigarette monopoly in Tokyo...have found that the incidence of lung cancer in Japan is linked with industrial smog areas rather than the number of smokers. ${ }^{\prime 18}$

- 1964: "The researchers concluded that "no statistically demonstrable connection" could be found between cigarette smoking and lung cancer. They further asserted that "other external influences", particularly air pollution, had to be considered in the increasing occurrence of lung cancer." 19

- 1964: "Dr. Poche and his associates say unequivocally that air pollution is the most likely suspect cause and explain the paradox of agricultural risks in terms of implement diesel fumes, chemical sprays, exposure to colds and to polluted air from nearby towns."20

- 1970: Dr John Wyatt, Professor of Pathology at Canada's University of Manitoba, toured Australia for the tobacco industry: ". ..one important avenue of research was the role of air pollution." ${ }^{\prime 21}$ 


\section{Box 2: Everything can cause cancer}

- 1969: "Last month we reported that Aspirin had joined the club of health hazards according to a Melbourne doctor, who claimed it induced kidney disease. ... Now more items in general use have also fallen under suspicion and received world-wide publicity following action taken in the United States." The article then ridiculed panic about cyclamates and monosodium glutamate, arguing that scaremongering was becoming rampant. ${ }^{22}$

- 1967: "Bread and tea, as well as cigarette smoke and air pollution have been indicated as possible causes of cancer...the bread comes into direct contact with cancer-causing agents produced by burning fuel...a study had indicated that tea contained properties...which promote or enhance the activity of cancer initiators..." 23

- 1971: "Coffee drinking may cause cancer of the bladder, a group of American scientists said in an article published recently in the British medical magazine "The Lancet". ${ }^{24}$

- 1976: Under the headline Join the club: "A red dye commonly used to colour cereals, cosmetics, sweets, jams and medicines, will be investigated by the Australian Health Department because of a suspected link with cancer." 25

- 1977: "Fructose, a sweetener used extensively in diet soft drinks, may pose as big a health threat as the suspected cancer-causing agent saccharin..." 26

- 1977: "The trend towards shorter haircuts for young Australians is disastrous for health, according to an American professor. "It can only increase the alreadydangerous level of skin cancer complaints..." 27

tobacco-cancer link was greatly over-rated, adding: "the chance of a smoker contracting lung cancer depends on the health of the individual smoker and his susceptibility to lung cancer." 28

In 1963, the year after the publication of the Royal College of Physicians report, the Victorian Tobacco Journal published a statement from Rothmans' chairman: "The subject of health continues to cloud the industry. A great deal of emotionalism surrounds the question, and the issue has been magnified out of all proportion, if only because it is fashionable to attack the tobacco industry. There is much public misconception as a result... The fact remains that the theory is still only a theory, and there has been no clinical or laboratory confirmation. Indeed, it seems to be ignored that other factors must be at work... It is unquestionably wrong, and irresponsibly wrong, to publicise smoking as the sole culprit, even if the "evidence" proved it to be one of the culprits." 29

In 1970, following calls for Australian packs to carry health warnings, the Australian Retail Tobacconist ran material emphasising that anti-smoking claims were being made by inexpert people who were simply wrong: "...Two members of the U.S. Government committee which conducted the 1969 inquiry made these comments in the official report: Congressman Richardson Preyer-" Like most of the public, I thought that a case against tobacco had been made by disinterested and well-informed groups acting on behalf of the public... This was very naive... For example, not a single witness for the anti-smoking forces testified to any research which he himself had done, while over 20 witnesses testified in person or by written statement that their own research cast serious doubts on the theory that cigarettes cause disease."

Congressman David E. Satterfield: "Perhaps the most disturbing aspect of the hearings before our committee was that the highly qualified pathologists, thoracic surgeons, general practitioners, and statisticians were able to demonstrate that certain published and well-known statements dealing with smoking, which have been accepted as true, are in fact false and without basis." The official committee report also makes this statement: "On the basis of these hearings the committee concludes that nothing new has been determined with respect to the relationship between cigarette smoking and human health since its hearings in 1964 and 1965." ${ }^{\prime 30}$

In 1970 two retail journals ${ }^{31} 32$ re-published an industry "memorandum to smokers" brochure containing a smorgasbord of quotations from doctors and scientists criticising antismoking propaganda such as: "The concept that cigarette smoking is the cause of the increase in lung cancer and emphysema is a colossal blunder."-Dr. Milton B. Rosenblatt, President of Medical Board, Doctors Hospital, New York (fig 1).

\section{Safe cigarettes imminent}

Several articles emphasised that the tobacco industry was deeply committed to finding and then removing any problematic ingredients in tobacco, and to changing its manufacturing process to produce "safe" cigarettes. The irony of this (in light of the constant denial that tobacco was harmful) was apparently lost on the industry: "We shall endeavour to produce such a safe cigarette and we believe that simple loose rolling of 'roll your own' cigarettes is also quite satisfactory." ${ }^{33}$ Other articles emphasised developments in filter technology ${ }^{34}$ and agricultural practices said to greatly reduce the potential harm of cigarettes. If communicated to smokers, these ideas may well have offered reassurance that safe smoking was imminent, perhaps delaying decisions to quit: "A new cigarette which the manufacturers claim carries a reduced cancer risk has gone on the market in U.S.A. Officials of the Continental Tobacco Company, of Colombia, South Carolina, say their new cigarette, Venture, has reduced cancer-causing properties because its tobacco is grown without the use of pesticides ...Continental's president, Mr. James Sorensen, said the company had eliminated or controlled two broad categories of cigarette tar components which may be related to certain lung disorders...in their search for a safer smoke, two American scientists have come up with a new filter that they claim could cut by 92 per cent a radioactive substance that has been linked with lung cancer..." ${ }^{35}$

Exotic anomalies were publicised, such as an account of "Ecuadorian peasants in a 1,500ft. high valley who drank rum and smoked many cigarettes every day were still able to till soil when well over 100 years old... The peasants...drank two to four cups of rum and smoked anything from 40 to 60 cigarettes a day." ${ }^{\prime 36}$ The tobacco industry later realised that the Ecuadorian situation arose because "it turned out that they didn't inhale." ${ }^{37}$

\section{Committed to research}

Like the manufacturing industry, the retail journals pushed the argument that the industry was vitally committed to researching the real causes of cancer, the assumption being that tobacco would either be exonerated or that any problematic elements in tobacco could be easily eliminated, allowing smokers to continue smoking in safety: "American cigarette manufacturers in the past 12 years have spent over $\$ 9$ million for health research through the Council for Tobacco Research, U.S.A., which has made some 613 


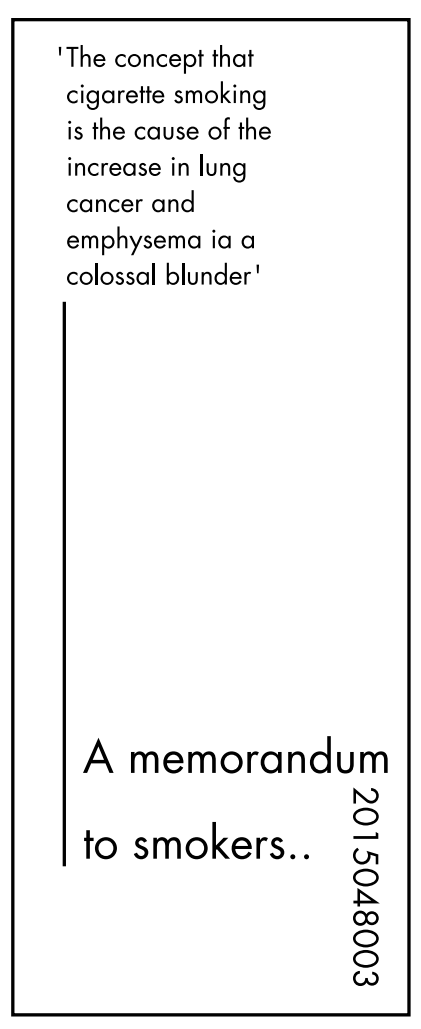

Figure 1 Smokers' brochure republished in retail journals in 1970.

no-strings-attached grants for independent research into the health problem. ...The cigarette industry insisted on all-out research to find out how the diseases mentioned in the report developed, whether cigarette smoking had anything to do with it and if it does, how to remove the hazard." ${ }^{38}$

Local research initiatives by Australian companies were also publicised, appealing to notions that disease aetiology was likely to follow unique patterns in each country, the corollary being that international studies could be dismissed as irrelevant to local conditions: "It is intended that the Foundation should concern itself specifically with smoking and health research in the Australian environment... Our independent research project has been prompted by the fact that too little is known scientifically of the smoking and health problem in a wholly Australian context... We believe that there has been too strong a predisposition to accept the results of statistical analyses and certain experiments in other countries as being applicable to Australia." ${ }^{\prime 39}$

\section{Anti-smokers: alleged experts and killioys}

Anti-smokers also came in for comment in the journals. They were "made up of a lot of po-faced people who are quite often, or so my prejudices insist, in favour of legalising soft drugs. This thought is prompted by the news that the president of the Australian Council on Smoking and Health, Dr. W. C. B. Harvey, this week described as deplorable the fact that the 200 Australian soldiers still serving in Vietnam are to be presented with Father's Day gifts of cigarettes, cigars and tobacco. Only one thing is deplorable here, and that is that Dr. Harvey should have made his petty-minded objection. Hundreds of thousands of people [gain] the innocent pleasure from smoking - and the world is full of old smokers." ${ }^{40}$

Those warning about smoking were "alleged" scientists, people "posing as experts", and "killjoys" deserving ridicule. Such articles played to populist notions of scientists as lacking the ordinary person's ability to see through nonsense and who hoodwinked the public with implicitly untrustworthy "statistics": "We take note again of the alleged scientists, reformers and Dr. Killjoys who keep telling us all we'll live longer by staying away from cigarettes... The Dr. Killjoys et al. admit that their evidence is purely statistical. That means they collect coincidences - cases of people who (1) smoked cigarettes and (2) died eventually of lung cancer or heart trouble-and then conclude that the cigarettes caused the fatal diseases. There is no laboratory evidence that cigarettes ever gave lung cancer or heart disease to a single human... let's play for a moment with the notion that you'll live longer statistically if you don't smoke. Taking off from that notion, you can work out a statistical formula for living, not merely longer, but forever. Here's how you do it...statistically, the way to live forever is simply to refrain from eating, drinking water, and breathing...let's go on giving the horselaugh to the enemies of the cigarette." ${ }^{41}$

A good example of such ridicule was in a 1969 article "Do horses smoke?": "...Yet horses have been found to suffer from the lung disease, emphysema, for which some public health authorities...blame cigarettes...but the National Institute of Allergy and Infectious Diseases announced firm findings that...the cause or causes of emphysema are not now known." 42

Anti-smoking efforts were said to be "hysterical" and populist: "Politicians everywhere are slowly giving into the hysteria of the anti-smoking lobby and proposing more and more restrictions on this long-standing pleasure of millions. These days it seems to be the "in thing" for politicians to knock the tobacco trade and ignore the more sensitive problems of poverty, pollution, pornography and pot.." ${ }^{43}$

\section{"Excessive" smoking is the problem}

By 1972, there were signs that the retailers had begun to modify their position on smoking and health, with one editorial noting: "...we have no wish to play down the indisputable health hazard of excessive cigarette smoking." ${ }^{44}$ Another visiting consultant for the industry, WB Ober: “...told a press conference that...ordinary cigarette smoke carried no appreciable risk...although excessive smokinglike any other sort of abuse-might do some harm. ... No-one has investigated the effects of very heavy smoking." 45 The Tobacco Workers Union duly picked up this message and called for: "an ending of the attacks on the harmless habit of smoking in moderation. ...No one denies that excessive smoking, together with other factors, like industrial pollution and car exhausts, can cause damage to the lungs. But no one is prepared to give credit to smoking for quietening the nerves and relaxing millions of people caught up in the industrial rat race. Mental and nervous stress in the automated factory, plus the striving for better conditions of living for the worker and his family, produce a situation in which the desire for smoking becomes impossible to resist" ${ }^{\prime \prime 6}$

\section{"Nobody ever argues against going after young customers...": recruiting smokers}

The industry also used the journals to advise retailers on how they might interest non-smokers and "novices" in smoking. Despite cigarette sales to minors having been illegal in most Australian states since the end of the 19th century ${ }^{47}$ the journals acknowledged the importance of the teenage market. The journals are rich sources of candour about the importance of attracting youth.

1953: “...it is important enough for each industry to try to get as much of the market as possible of young customers for its products... After all, they are still at an age when they can be influenced in their buying habits...they are at an age of enthusiasm where if they like something, they try to get all their friends to go along." 48 
1954: "One of the most important customers today is the youthful novice in smoking. He is your customer of the future and special efforts should be made to cultivate him..." ${ }^{\prime 49}$

1964: "Statistics show that 12 per cent of the population in Australia are teenagers and represent 16 per cent of the total purchasing power... The importance of wooing this group with advertising is therefore evident. Surveys show that teenagers are most responsive to advertising, and when it appears in a form slanted to them directly, it becomes a valuable springboard for capturing this lucrative market...The habit of magazine readership built up through such a teenage paper carries through to adulthood. ...To the far-sighted advertiser, this is one of the most important aspects of the teenage market - it is the adult market of tomorrow." 50

Specific suggestions to attract young customers were provided, ranging from sales advice to shop layout and particularly the attractions of smoking accessories such as cigarette cases and holders: "... and we should certainly go after them strong with smokers' accessories... Nobody ever argues against going after young customers...for example they must be made to feel that it is stylish to have a dressy cigarette case, to have a cigarette holder, to have a well-styled pouch. The magazines are full of colour pages showing young fellows how to be better groomed and better turned out, and certainly it should not be too difficult to get them to add wellstyled smokers' accessories to the list of things a wellgroomed young fellow has...Keep something stylish up on top all the time and you build yourself a reputation for attracting young buyers-and no matter where he is or who he is, you want him to become a customer for smokers' accessories... Every other type of product is boomed and boosted in the scramble for a share of the wage packet. The tobacco trade cannot afford to stand back...We need more positive promotion-in advertising and displays, and in over the counter salesmanship-if we are to create regular customers out of hesitant young smokers...The persistent theme in trying to attract the youthful smoker is that the cost need not be excessive, and that the pleasure to be gained is more than worth the cost. But the trade must drive home this message and not wait for the youngster to discover it for himself. He might never do so." ${ }^{49}$

\section{Women}

Women were also seen as a critical target group, not only for their own potential as smoking customers, but as gatekeepers important in influencing their families' smoking:

1954: "We all know that women do in fact comprise quite a big part of the smoking population... Any change ought to be in an upward direction... Perhaps the biggest opportunities are offered by young women smokers. They are at the receptive age at which habits are formed, and a special campaign to attract such customers may well yield dividends for years to come." ${ }^{51}$

1956: A sales guru advised "... women are one of the prime deciding factors on what brands of produce come into the home. In America where the house-wife will buy a whole carton of cigarettes at a time while marketing, she can gradually accustom the rest of the family towards smoking her choice of cigarettes." ${ }^{52}$

Judging by an almost total absence of female retailers named or profiled in the journals, the vast majority of retailers were probably male, and it was considered that they required special instructions in smalltalk for selling to the opposite sex whose mysterious predilections were revealed thus: “...To her a goodly array of nicely displayed goods is the biggest attraction a tobacco shop can offer...something more is needed than merely handing over a packet of the requested brand. Women enjoy special, individual attentions. There could be more interest in the job in many shops-a greater keenness to introduce new lines and to make suggestions... Women are especially affected by personal cleanliness and neatness of dress on the part of the salespeople." ${ }^{\prime \prime 1}$

"Winter, when the housewife is even more likely to purchase the week's smokes at the supermarket when she gets the family groceries. This is the time of the year when your business premises should look particularly attractive. The time when you should put forward your best efforts at salesmanship. "It looks like being a stormy weekend" you might well say to your next customer, adding quietly, "Have you made certain that you've enough smokes to see you through?" Then, apparently as an afterthought: "It's much better sitting at home by the fire these days than having to come out shopping for something you've run out of." ${ }^{153}$

\section{DISCUSSION}

We have presented illustrative examples of efforts to take the "heat" off tobacco from a large sample of the Australian retail tobacco industry literature published between 19501978. If, as the tobacco industry intended, tobacconists did indeed pass this sort of information onto their customers, then many smokers alive today who commenced smoking during this 28 year period would have been exposed to this "reassurance" strategy. The modal age for smoking initiation in Australia is 15 years of age. Thus many smokers born between 1935 (today therefore aged 68) and 1963 (today aged 40) are likely to have often bought their cigarettes at dedicated tobacconists who subscribed to these journals. These smokers may therefore have been subject to the sort of persuasion urged or implied by the authors of the articles we have excerpted.

A core platform of the tobacco industry's defence against litigation from sick and dying smokers claiming damages in the courts is to argue that smokers are fully informed about the risks of smoking and therefore should bear all responsibility for their decision to smoke. Despite having fought hard to keep health warnings off packs ("Obviously the Group policy should be to avoid health warnings on all tobacco products for just as long as we can" $),{ }^{54}$ and to then keep those warnings as non-specific as possible ("As you know, it has been our policy to resist any mention of specific diseases"), ${ }^{55}$ the industry also shelters behind the defence that all cigarette packs have featured a health warning in Australia since 1973.

Against this, counsel for such litigants typically argue that smokers were inadequately warned about the magnitude and probability of the risks they faced; that the tobacco industry actively worked to prevent, delay and weaken health warnings on packs; that the industry targeted them as children when they were below an age when they could meaningfully comprehend the risks they faced; that the addictiveness of nicotine and the industry's efforts to deny that cigarettes were addictive undermined smokers' ability to exercise free choice; and that the industry sought actively to falsely reassure smokers that there was widespread disagreement in the scientific community that smoking was harmful to health.

In 1987, a small Sydney pilot study of smokers reported that $59 \%$ of smokers agreed that "everything causes cancer these days". ${ }^{56}$ Larger Australian studies in 1991 and 2002 found that $42 \%$ (1991) and 24\% (2002) of smokers agreed with the statement "Most lung cancer is caused by air pollution, petrol fumes, etc" and 45\% (1991) and 22\% (2002) believed that "the medical evidence that smoking causes cancer is not convincing". ${ }^{57} 58$ Such findings are consistent with an hypothesis that the tobacco industry's efforts to dissemble the evidence on smoking and health is likely to have contributed to the formation of such widespread beliefs 


\section{What this paper adds}

The tobacco manufacturing industry's efforts to reassure smokers about the alleged harms of tobacco use are now well documented.

This is the first study to examine the role played by tobacco retailers in acting as a conduit to smokers for information offen supplied by the tobacco manufacturers about smoking and health. Between 1950-1978 heavy emphasis was placed on air pollution (not smoking) causing lung cancer; on how "experts" believed everything was dangerous; on how the industry was dedicated to making safer cigarettes; and on how only "excessive" smoking might be dangerous. In the 1950s and early 1960s, tobacco retailers openly targeted youth and women in their sales pitches.

in the Australian community. The material summarised in this paper should prove useful in litigation, complementing evidence of the tobacco manufacturing industry's efforts to falsely reassure smokers.

\section{ACKNOWLEDGEMENTS}

The research reported in this paper was supported by a grant from the National Health and Medical Research Council (2001-2003 \#153857).

\section{Authors' affiliations}

A Tofler, S Chapman*, School of Public Health, University of Sydney, Sydney, Australia

*Also Associate Director, VicHealth Centre for Tobacco Control

\section{REFERENCES}

1 Francey N, Chapman S. "Operation Berkshire": the international tobacco companies' conspiracy. BMJ 2000;321:371-4.

2 Cummings KM, Morley CP, Hyland A. Failed promises of the cigarette industry and its effect on consumer misperceptions about the health risks of smoking. Tobacco Control 2002;11(suppl I):i1 10-i17.

3 Bero LA, Barnes DE, Hanaver P, et al. Lawyer control of the tobacco industry's external research program: the Brown and Williamson documents. JAMA 1995;274:241-7

4 PriceWaterhouseCoopers. The significance of cigarettes and tobacco products to retailers: an analysis of retail sales 1999. British American Tobacco Australia. Last updated: 12 Mar 2003. Date accessed: 21 Jul 2003. http:// www.bata.com.au. (Industry Information - Retail Sector)

5 Carter SM. Going below the line: creating transportable brands for Australia's dark market. Tobacco Control 2003;12(suppl III):iii87-94.

6 Anon. Retail price list-Important. Tobacco Trade Journal (Queensland); 12(7):9.

7 Anon. Transport smoking ban. Australian Retail Tobacconist 1977;38(4):5.

8 Anon. Health warning on cigarettes. Australian Retail Tobacconist 1973;34(5):4.

9 Doll $R, H i l l A B$. Smoking and carcinoma of the lung: preliminary report. BMJ 1950;2:739-48.

10 Wynder EL, Graham EA. Tobacco smoking as a possible etiologic factor in bronchiogeneic carcinoma. JAMA 1950;143:329-36.

11 Royal College of Physicians of London. Smoking and health. New York: Pitman Publishing Corp, 1962

12 US Department of Health Education and Welfare. Smoking and health: report of the Advisory Committee to the Surgeon General of the Public Health Service. Washington, DC: U.S. Dept. of Health, Education, and Welfare, Public Health Service, 1964. (Public Health Service publication no. 1103).

13 Anon. The scare. Tobacco Trade Journal (Queensland) 1953;12(6):19-20.

14 Anon. Handling "loose talk" about cigarettes. Tobacco Trade Journal (Queensland) 1955; 14(7):26

15 Anon. Lung cancer. Tobacco Trade Journal (Queensland) 1959;18(8):8.

16 Anon. Chest surgeon on lung cancer. Tobacco Journal (Victoria) 1962;32(3):45
17 Anon. "Little risk in smoking", doctor writes. Tobacco Trade Journal (Queensland) 1963;22(2):22.

18 Anon. World reaction to Surgeon General. Tobacco Trade Journal (Queensland) 1964:23(5):4.

19 Anon. Smoking and health: doubt on smoking link. The Tobacco Journal (South Australia) 1964;19(6):6-7.

20 Anon. German report ... blames air pollution. Tobacco Trade Journal (Queensland). 1964;23(10): 3, 4, 6

21 Anon. Risk in smoking "exaggerated". Australian Retail Tobacconist 1970;31(6):6.

22 Anon. More join the club. Australian Retail Tobacconist 1969;30(5):5.

23 Anon. Smoking and health: bread, tea blamed for cancer. Tobacco Trade Journal (Queensland) 1967;(1):18.

24 Anon. Coffee-cancer link. Australian Retail Tobacconist 1971;32(10):4.

25 Anon. Join the club! Australian Retail Tobacconist 1976;37(5):5.

26 Anon. Fructose may be health threat. Australian Retail Tobacconist 1977;38(10):6.

27 Anon. Now short hair's a cancer risk. Australian Retail Tobacconist 1977;38(10):6

28 Anon. Cancer link overated says Dr. Charles Mayo. Tobacco Trade Journal (Queensland) 1962;21(11):21.

29 Anon. Statement by Rothmans chairman. Tobacco Journal (Victoria) 1963;33(2): 13, 15

30 Anon. The cigarette-cancer dispute. Australian Retail Tobacconist 1970;31(8): 10

31 Anon. Memorandum to smokers. Australian Retail Tobacconist 1970;31(6):6.

32 Anon. Memorandum to smokers. Tobacco Journal (Victoria) 1970;39(9):5.

33 Anon. Expert's "cancer safe" cigarette. Tobacco Journal (Victoria) 1967;36(7): 15

34 Anon. How Lark took flight. The Tobacco Journal (South Australia) 1964;19(8):19-20.

35 Anon. A new "safe" smoke. Tobacco Journal (Victoria) 1967;36(12):16.

36 Anon. Long life formula. Australian Retail Tobacconist 1973;34(3):4

37 Lincoln J. [Interoffice memo to Mr Norman Janelle]. 24 Nov 1980. Philip Morris. Bates No. 2024258054/8055. http://legacy.library.ucsf.edu/tid/ lyk98e00.

38 Anon. Nicotine and tar. Tobacco Journal (Victoria) 1967;36(6):5.

39 Anon. Australian manufacturers to finance health research. Tobacco Journal (Victoria) 1969:38(11):13.

40 Anon. The war on smokers. Australian Retail Tobacconist 1972;33(9):7

41 Anon. Live forever?: here's how. Tobacco Journal (Victoria) 1963;33(3):13.

42 Anon. Do horses smoke? Tobacco Journal (Victoria) 1969;38(12):9.

43 Anon. The war on smoking. Tobacco Trade Journal (Queensland) 1974;33:4.

44 Anon. The anti-smoking campaign. Australian Retail Tobacconist 1973;34(11):4

45 Anon. Smoking defended by US professor. Tobacco Trade Journal (Queensland) 1972:31(4):4.

46 Anon. Hands off the little smoker. Tobacco Trade Journal (Queensland) 1973;32(11):16.

47 Tyrrell I. Deadly enemies: tobacco and its opponents in Australia. Sydney: UNSW Press, 1999.

48 Anon. How to attract young customers. Tobacco Trade Journal (Queensland) 1953;22(3):20-21.

49 Anon. Ways to encourage the young smoker. Tobacco Trade Journal (Queensland). 1954;13(5): 11, 24.

50 Anon. How important is the teenage market? Tobacco Journal (Victoria) 1964;33(5/6):21

51 Anon. Four ways to put off that woman customer: taste should be created in the young woman smoker. Tobacco Trade Journal (Queensland) 1954;13(6): 18, 24

52 Anon. Philip Morris executive visits Australia. Tobacco Trade Journal (Queensland) 1956;15(7):7-8

53 Anon. Winter is back again. Tobacco Trade Journal (Queensland) 1971;30(6):5.

54 Lockhart C. Health warnings Germany [Letter to D von Specht]. BritishAmerican Tobacco Company. 21 Jul 1978. Guildford. Bates No. 301082507. Accessed $21 \mathrm{Jul}$ 2003. http://tobacco.health.usyd.edu.au/tds/ BAT301082507.

55 Ely R. Warning labels - USA [Letter to all No. 1s of operating companies]. British-American Tobacco. 20 Jun 1984. Guildford. Bates No. 100145188. Accessed $21 \mathrm{Jul}$ 2003. http://tobacco.health.usyd.edu.au/tds/ BAT100145188.

56 Chapman S, Rubinstein P. Smokers' beliefs about smoking and health Med J Aust 1987; 146:502-3.

57 Chapman S, Wong WL, Smith W. Self-exempting beliefs about smoking and health: smoker and ex-smoker differences in a low socio-economic sample. Am J Public Health 1993;83:215-9.

58 Oakes W, Chapman S, Borland R, et al. Bulletproof skeptics in life's jungle: which self-exempting beliefs about smoking most predict lack of intention to quit? 2003. School of Public Health, University of Sydney (forthcoming). 